\title{
Developmental dynamics between young adults' life satisfaction and engagement with studies and work
}

\author{
Katja Upadyaya \\ katja.upadyaya@gmail.com \\ Katariina Salmela-Aro
}

(Received January 2016
University of Jyväskylä, Finland, University of Helsinki, Finland

University of Jyväskylä, Finland, University of Helsinki, Finland

\section{Abstract}

Revised July 2016)

http://dx.doi.org/10.14301/llcs.v8i1.398

The present five-wave longitudinal study investigated the cross-lagged associations between young adults' life satisfaction and study/work engagement over the transition from postcomprehensive studies to higher education or work during the second and third decades of life. Gender, educational track, academic performance and family socioeconomic status were also examined. The study is part of the longitudinal Finnish Educational Transitions (FinEdu) study, and used data from secondary education onwards, following 821 participants from age 17 to 25 . The developmental dynamics showed that, in particular, young adults' life satisfaction predicted their study/work engagement both during their post-comprehensive education and after the transition to higher education or work. Moreover, study/work engagement positively predicted young adults' life satisfaction during their third decade of life. In addition, high initial life satisfaction was more typical among males. However, no differences related to gender or academic track were observed in the developmental dynamics of life satisfaction and study/work engagement. These results suggested that general wellbeing spills over to study/work domainspecific characteristics of wellbeing and promotes positive personal development and adjustment to study/work transitions during the third decade of life.

\section{Keywords}

Life satisfaction, study/work engagement, study/work transition, young adults, longitudinal studies 


\section{Introduction}

The third decade of life is a period during which individuals are faced with more role transitions and life decisions than at any other life stage (Caspi, 2002). Rindfuss (1991) describes the period between the ages of 18 and 30 as demographically dense, as many key role transitions take place then, including moving from education to employment (Elder \& Shanahan, 2006). Moreover, at the moment the global economic crisis is affecting Finland and young people need to navigate to adulthood in challenging times. Thus, during the third decade personal (e.g., life satisfaction) and study/work-related wellbeing (e.g., engagement) become increasingly important.

Engagement with studies and work is characterised by a committed study- and work-related mindset (Fredricks, Blumenfeld, \& Paris, 2004; Li \& Lerner, 2011; Schaufeli, Salanova, Gonzalez-Roma, \& Bakker, 2002), which predicts many long-term positive outcomes, such as higher education, academic success (Annunziata, Hogue, Faw, \& Liddle, 2006), better job prospects (Upaydyaya \& Salmela-Aro, 2013b), and positive self-perception (Linnakylä \& Malin, 2008). Life satisfaction reflects one's general happiness and wellbeing (Lewis, Huebner, Malone \& Valois, 2011), whereas study/work engagement, similar to flow (Csikszentmihalyi, 1990), describes one's domain-specific experiences and wellbeing (Hakanen \& Schaufeli, 2012; Upadyaya \& Salmela-Aro, 2013a). Despite these differences, satisfaction in life is often associated with study/work engagement during different life stages. For example, high engagement in studies is positively associated with life satisfaction in middle school (Lewis et al., 2011), and also manifests as an increase in life satisfaction after finishing vocational/high school education (Salmela-Aro \& Upadyaya, 2014). Work engagement, in turn, predicts one's subsequent life satisfaction over several years (Hakanen \& Schaufeli, 2012). These previous results also suggest that various positive gain spirals and developmental cascades occur between study/work engagement and life satisfaction across different life stages (see also Masten, Desjardins, McCormick, Kuo, \& Long, 2010). However, to the authors' knowledge, life satisfaction and study and work engagement have not been examined longitudinally in the same study, focusing on young adults' transition to higher education/work and taking into account developmental cascades across life stages. The present study seeks to fill this gap by following young adults from their second to their third decade of life.

\section{Life satisfaction}

Increasing interest in life satisfaction reflects the growing attention to positive psychology, which focuses on human strengths and optimal functioning rather than on weaknesses and malfunctioning (Hakanen \& Schaufeli, 2012; Seligman \& Csikszentmihalyi, 2000). Life satisfaction is an important indicator of positive psychological wellbeing (Huebner, Valois, Paxton, \& Drane, 2005), as it describes one's general happiness and cognitive assessments of life quality based on one's own standards (Erdogan, Bauer, Truxillo, \& Mansfield, 2012; Lewis et al., 2011; Pavot \& Diener, 1993). At the beginning of their third decade Finnish young adults often face several transitions simultaneously (e.g., moving out from the childhood home, transitioning to new educational institutions/work, changes in social networks). They face increasing environmental and personal demands (e.g., adjusting to the place of study/work and to more independent life, attaining competence in studies/work) and decreases in the social support they received previously (see also Suldo \& Huebner, 2006). Thus, satisfaction with life may serve as a personal resource that promotes adjustment (Cohn, Fredrickson, Brown, Mikels, \& Conway, 2009) and becomes increasingly important at the beginning of the third decade when young adults are starting their careers and adjusting to their new work environments (see also Arnett, 2000). However, despite the positive associations between life satisfaction and academic (e.g., achievement, competence, school satisfaction; Suldo, Riley, \& Shaffer, 2006) and work outcomes (e.g., job performance, commitment), only a few studies have examined the associations between life satisfaction and academic- (Lewis et al., 2011) and work-related wellbeing (Erdogan et al., 2012). These studies have shown that most adolescents and young adults report positive global life satisfaction, although variation exists across domains; middle-school and high-school students typically report higher dissatisfaction with their school experiences compared to other life domains (Huebner, Drane, \& Valois, 2000; Huebner et 
al., 2005). Moreover, young adults who have received the high school diploma report higher levels of life satisfaction than their peers who obtained only general educational development tests or dropped out of school (Ou, 2008). Among adult workers, life satisfaction is positively associated with several workrelated variables, such as organisational commitment and personal growth (Erdogan et al., 2012); some evidence suggests that life satisfaction is more strongly related to job performance than job satisfaction (Jones, 2006).

Moreover, gender differences may exist in life satisfaction. Although some studies have reported higher study satisfaction among females than males, gender differences in global life satisfaction have been mixed, with some studies reporting similar levels of life satisfaction among females and males (Elmore \& Huebner, 2010; Huebner et al., 2000), and other studies reporting higher life satisfaction among males than females (Diseth, Danielsen, \& Samdal, 2012). Moreover, a notable amount of spillover exists between different variables related to work (e.g., job involvement, stress, satisfaction) and personal life (e.g., family conflict, stress, satisfaction) (Ford, Heinen, \& Langkamer, 2007), and thus, feelings of study/work engagement may be reciprocally related to overall experiences of life satisfaction. Further, typically, satisfaction with life is relatively stable over time, although the antecedents and outcomes of life satisfaction may vary at different ages and life stages (Myers \& Diener, 1995). For example, the influence of family socioeconomic status (SES) on life satisfaction may be more pronounced among children (Seligson, Huebner, \& Valois, 2003) than adults (Louis \& Zhao, 2002).

\section{Study and work engagement}

Recent research suggests that the underlying construct of engagement is the same for students and employees (Wefald \& Downey, 2009). Studies drawing on the work engagement literature (Hakanen, Bakker, \& Schaufeli, 2006; Salanova, Agut, \& Peiro, 2005; Schaufeli, Bakker, \& Salanova, 2006) have examined students' and workers' psychological engagement resembling flow (Csikszentmihalyi, 1990) in detail, including the dimensions of energy, dedication, and absorption while studying or working (Salmela-Aro \& Upadyaya, 2012; Schaufeli, Salanova,
Gonzalez-Roma, \& Bakker, 2002; Upadyaya \& SalmelaAro, 2014). Flow refers to an experience which itself is so enjoyable that people tend to pursue it, even at great cost, purely for the sake of the experience (Csikszentmihalyi, 1990). However, the main difference between the concepts of flow and engagement is that flow refers to a short-term (however, often recurrent) peak experience that occurs infrequently in studies/work, whereas engagement is a more general and persistent state of mind. Energy refers to high mental resilience and affects while studying, a willingness to invest effort in one's schoolwork, and a positive approach. Dedication, in turn, is characterised by a sense of significance, enthusiasm, pride, and inspiration regarding school, as well as perceiving schoolwork as meaningful. Absorption is characterised by behavioural accomplishments, fully concentrating and being happily engrossed in one's studying so that time passes quickly. These three dimensions are distinct analytic constructs of study and work engagement, although they correlate highly with each other (Salmela-Aro \& Upadyaya, 2014; Schaufeli et al., 2002). They may be considered as a one-dimensional or as a three-dimensional construct, depending on the research purpose (Seppälä et al., 2009). Either approach elucidates the development of engagement during the school-to-work transition in association with general wellbeing (see also Dietrich, Parker, \& Salmela-Aro, 2012 for phase specific engagement; Haase, Heckhausem, \& Köller, 2008).

Moreover, differences related to gender and socioeconomic status may influence study/work engagement: females typically experience higher levels of overall study engagement than males (Marks, 2000; Salmela-Aro \& Upadyaya, 2014), probably because female students tend to perform better academically (Pomerantz, Altermatt, \& Saxon, 2002) and attribute greater importance to academic achievement than males (Berndt \& Miller, 1990). Similarly, males and students from lower income families are more likely than females and students from higher socioeconomic backgrounds to experience rapid decrements in engagement and to follow unstable school engagement trajectories which may sometimes lead to school dropout (Archambault, Janosz, Morizot, \& Pagani, 2009; Li \& Lerner, 2011). 
Moreover, in some countries men score higher in their engagement with work whereas in other countries the reverse is true (Schaufeli et al., 2006). The fact that not all studies report gender differences in student (Simons-Morton \& Crump, 2003) or employee engagement (Langelaan, Bakker, Doornen, \& Schaufeli, 2006) highlights the need for further research in different societal contexts.

High academic performance also promotes high engagement in studies (Li \& Lerner, 2011; Salmela-Aro \& Upadyaya, 2012) and in work (Upadyaya \& SalmelaAro, 2013b). Further, compared to their peers following a vocational track, young adults on an academic track often feel more exhausted and less engaged in their studies (Salmela-Aro \& Upadyaya, 2012), which may also manifest in the associations between study/work engagement and life satisfaction.

\section{Study/work engagement and life satisfaction}

According to the demands and resources model (Demerouti, Bakker, Nachreiner, \& Schaufeli, 2001), high engagement protects against malaise and burnout symptoms, and leads to wellbeing and high life satisfaction (Salmela-Aro \& Upadyaya, 2014). Similarly, spillover exists between study- and workdomain specific wellbeing/ill-health and between general wellbeing/ill-health (Hakanen \& Schaufeli, 2012; Salmela-Aro \& Upadyaya, 2014; Upadyaya \& Salmela-Aro, 2016; in press). Thus, positive development in one life domain (e.g., general wellbeing and life satisfaction) may influence adaptation in other life domains and promote domain-specific wellbeing, reflecting developmental cascades that occur during the second and third decades and earlier (see also Masten et al., 2010). In addition, the 'broaden-and-build' theory suggests that students who are satisfied with their studies and life, and experience frequent positive emotions, will exhibit adaptive coping behaviours, feel more engaged, and gain more resources which, in turn, will promote positive upward spirals of success at studies/work (see also Fredrickson, 2001). These positive cycles may become especially important during the third decade of life when decreases occur in the social support young adults typically receive (see also Suldo \& Huebner, 2006) as they simultaneously face various personal, educational, and work transitions and prepare for adult work roles (Arnett, 2000). At the same time young adults' personal agency becomes more important (Evans, 2007) and their lives are less structured than during the second decade. From the phase adequate engagement perspective (Dietrich et al., 2012), general wellbeing and study/work engagement are closely tied together especially after the transition to higher education or work when obtaining a good study/work status is one of young adults' most important goals. Life satisfaction, in particular, may serve as a cognitive resource, derived from frequent positive emotions, which helps in facing a wide range of life's challenges and supports positive personal growth (Cohn et al., 2009). Thus, high life satisfaction may promote study/work engagement, which, in turn, may lead to an increase in subsequent life satisfaction. Empirical studies have shown that engagement and life satisfaction are typically highly correlated with each other (Harter, Smidth, \& Hayes, 2002; Lewis et al., 2011). However, only a few studies have investigated the cross-lagged associations between engagement and life satisfaction (Lewis et al., 2011) and longitudinal studies are needed to examine these associations further during different developmental stages. Consequently, the present study aims at investigating the cross-lagged associations between young adults' life satisfaction and study/work engagement over a period of eight years, following young adults from their second to their third decade of life.

Variation in the associations between engagement and life satisfaction across the transition from postcomprehensive studies to higher education/work could reflect the changing fit between person and environment (Eccles \& Roeser, 2009) across grade levels and age (Fredricks et al., 2004). During their second decade and before the transition to higher education/work, young adults typically have various sources of support (e.g., parents, teachers, peers) that may promote their life satisfaction (Suldo \& Huebner, 2006), which spills over to domain-specific engagements. During the transition, when young adults are adjusting to their new study/work environments and finding their place in their new educational/work settings, associations between life satisfaction and study/work engagement may 
momentarily diminish. However, after the transition and at the beginning of their third decade when their new study/work environments become more salient, study/work engagement may increasingly predict life satisfaction. Consequently, to better understand the dynamics of life satisfaction and study/work engagement, the present study investigates the crosslagged associations between life satisfaction and study/work engagement as young adults make the transition from post-comprehensive studies to higher education studies/work.

\section{Schooling in Finland}

Compulsory comprehensive education in Finland lasts for nine years until the students are 16 years old. After that, approximately $50 \%$ of adolescents enter senior high schools and approximately $41 \%$ go to vocational schools (School Statistics, Central Statistical Office of Finland, 2010). Average academic achievement in the ninth grade is the minimum requirement for admission to senior high school. Both senior high schools and vocational education take three to four years to complete, after which students may apply to institutes of higher education. Approximately $39 \%$ of high school graduates start studying, $44 \%$ begin working, and $25 \%$ are studying and working one year after finishing high school, whereas $8 \%$ of young adults with a degree from a vocational school are studying, $69 \%$ are working, and $10 \%$ are both studying and working one year after their graduation.

\section{Hypotheses}

The aim of the present five-wave longitudinal study was to investigate the cross-lagged associations between life satisfaction and study/work engagement during and after the transition from postcomprehensive studies to higher education or work. In addition, the role of gender, academic performance, family socioeconomic status and academic track (e.g., vocational and academic track) in these associations was examined. Based on previous studies of developmental cascades (Masten et al., 2010)), phase adequate engagement (Dietrich et al., 2012), and study- and work domain-specific and general wellbeing (Hakanen \& Schaufeli, 2012; Salmela-Aro \& Upadyaya, 2014; Upadyaya \& SalmelaAro, 2015), we expected that spillover would occur between life satisfaction and study/work engagement. That is, these psychological constructs would be positively associated with one another both during post-comprehensive studies and after transition to higher education/work at the beginning of the participants' third decade. More specifically, and following the broaden-and-build theory (Fredrickson, 2001) we expected that life satisfaction predicts study/work engagement during the participants' second and third decade $(\mathrm{H} 1)$, whereas study/work engagement predicts life satisfaction more prominently after the transition to higher education/work and during the participants' third decade ( $\mathrm{H} 2)$. In addition, we expected that males and students with high academic performance would experience higher levels of life satisfaction (H3) (Diseth et al., 2012; Ou, 2008). Finally, we expected that females and students following a vocational track or with high academic performance would experience higher levels of study/work engagement (H4) (Salmela-Aro \& Upadyaya, 2012; 2014).

\section{Method}

The data were drawn from the Finnish Educational Transitions (FinEdu) study, which recruited all the ninth-grade students in a medium-sized town (population $=88,000$ ) in Central Finland. The present study used the data from post-comprehensive education onwards. Students from 13 postcomprehensive schools (six high schools and seven vocational schools) participated in the study. The first two years of measurements were carried out during each of the two post-comprehensive years: the first in 2005 at half a year after the transition to postcomprehensive school (Time 1, age $=17, N=818$ ) and the second one year later in 2006 (Time 2, age $=18, N$ $=749$ ). The third measurement was carried out two and a half years after Time 2 in 2009 (Time 3, age = $21, N=611$ ), when most of the students had already finished their post-comprehensive education. The fourth and the fifth measurements were carried out two (2011) and four years (2013) after Time 3 (Time 4 , age $=23, N=561 ;$ Time 5 , age $=25, N=533$ ). Thus, the data collection spanned the periods before, during and in the aftermath of the Great Recession.

Reflecting the general population in Central Finland (Kuopion Lukiokoulutus, 2009), the majority of the 
participants (99\%) were Finnish-speaking. The students most often lived with both parents (62\%), or with their mother or father, either as a lone parent $(25 \%)$, or living with her/his new spouse $(11 \%)$, or with somebody else (1\%). A total of $23 \%$ of the adolescents had siblings. The occupational distribution of the parents was as follows: $27 \%$ of the fathers and $20 \%$ of the mothers worked in higher white-collar occupations (e.g., medical doctors), $16.4 \%$ and $49 \%$ worked in lower white-collar occupations (e.g., teachers), $36 \%$ and $17 \%$ had bluecollar occupations (e.g., cooks, bus drivers), $11 \%$ and $4 \%$ were private entrepreneurs, $1 \%$ and $2 \%$ were students, $3 \%$ and $2 \%$ were retired, and $5 \%$ and $6 \%$ had some other status (e.g., unemployed). The occupational distribution is comparable to the general population in Eastern Finland. The questionnaires (Time 1-2) were group-administered to the students in their classrooms during regular school hours, and at Time 3-5 were mailed to the participants.

\section{Measures}

Study and work engagement were measured using the abbreviated student version of the Utrecht Work Engagement Scale, UWES-S (Salmela-Aro \& Upadyaya, 2012; for validity and reliability of the measure; Schaufeli et al., 2002; Schaufeli et al., 2006; Seppälä et al., 2009 for construct validity). At Times 1 and 2 the inventory concerned engagement in studies, and at Time 3-5 it covered engagement with studies or work, depending on the participant's current situation. The scale consists of nine items measuring energy (e.g., When I study/work, I feel that I am bursting with energy), dedication (e.g., I am enthusiastic about my studies/work), and absorption (e.g., Time flies when I'm studying/working) in relation to studies and work. The responses were rated on a seven-point scale ( $0=$ not at all; $6=$ daily), and an additive score was calculated to represent the participants' overall engagement in studies/work at each measurement time. To examine attrition between the measurements, young adults who participated in the study at each wave $(N=370)$ were compared with those who had missing data $(N=474)$. The results indicated that those young adults who participated in the study at each measurement showed higher engagement at Time $1(M=3.73, S D=$ $0.07)$, Time $2(M=3.65, S D=0.7)$, and Time $3(M=$
$4.40, \mathrm{SD}=0.06)$ than those who $\operatorname{did}$ not $(\mathrm{M}=3.45, \mathrm{SD}$ $=0.07, t(-2.97)=, p<.01 ; \mathrm{M}=3.32, \mathrm{SD}=0.08, t(-3.16)$ $=p<.01 ; \mathrm{M}=4.17, \mathrm{SD}=0.10, t(-2.16)=p<.05)$. At Times 4 and 5 no differences emerged in young adults' engagement due to attrition.

Life satisfaction was assessed using the five-item Satisfaction with Life Scale (Diener, Emmons, Larsen, \& Griffin, 1985). The items (e.g., I am satisfied with my life) were rated on a five-point scale ranging from 1 (I totally disagree) to 5 (I totally agree). An additive score was calculated from all five items at each wave. The attrition analyses showed that those young adults who participated in the study at each wave showed higher life satisfaction at Time $4(M=4.97, S D=0.06)$ and Time $5(\mathrm{M}=4.63, \mathrm{SD}=0.07)$ than those who did $\operatorname{not}(\mathrm{M}=4.67, \mathrm{SD}=0.09, t(-2.70)=p<.01 ; \mathrm{M}=4.20$, $\mathrm{SD}=0.10, t(-3.59)=p<.001)$. No differences emerged at Times 1-3 in young adults' life satisfaction due to attrition.

Academic performance was measured in accordance with the Grade Point Average (GPA) of the final comprehensive school report on a scale ranging from 4 (lowest) to 10 (highest).

Gender was coded 1 = female, $2=$ male.

School track (Time 2 ) was coded as $1=$ high school student $(N=529) ; 0=$ vocational school student $(N=$ 226);

Family SES was coded as 1 = blue collar, 2 = white collar.

Attrition analyses showed that females ( $\mathrm{M}=1.41$, $\mathrm{SD}=0.49)$ and students following an academic track $(M=1.79, S D=0.41)$ more often than males $(M=1.63$, $\mathrm{SD}=0.48, t(7.43)=p<.001)$ and students following $\mathrm{a}$ vocational track $(\mathrm{M}=1.59, \mathrm{SD}=0.49, t(-5.86)=p$ $<.001)$ participated in the study at all waves.

\section{Analysis strategy}

The aim of this study was to analyse the associations between study/work engagement and life satisfaction using cross-lagged path models. In these models, all the endogenous variables were allowed to covary. The tested model included stability coefficients for study/work engagement and life satisfaction, as well as cross-lagged paths between all the engagement and life satisfaction variables. The participants' gender, family SES, academic track, and performance were added in the model as 
antecedents of study/work engagement and life satisfaction (Time 1). In the final model, all of the statistically non-significant paths were set to zero. Moreover, in order to examine whether the models would show the same fit for males and females and for students on the academic and those on the vocational track, all the analyses were also carried out using the Mplus multigroup procedure (Muthén \& Muthén, 1998-2016).

The statistical analyses were performed using the Mplus statistical package (Version 6; Muthén \& Muthén, 1998-2016) with the missing data method. This missing data method uses all the data that are available in order to estimate the model without imputing the data. Because the distributions of the variables were skewed, the model parameters were estimated using the MLR estimator (Muthén \& Muthén, 1998-2016). Goodness-of-fit was evaluated using various indicators: $\chi^{2}$ test, Root Mean Square Error of Approximation (RMSEA), and the Standardized Root Mean Square Residual (SRMR). Because the $\chi^{2}$ test is sensitive to sample size, a relative goodness-of-fit index was also used to evaluate the model fit: the Comparative Fit Index (CFI). According to $\mathrm{Hu}$ and Bentler (1999), cutoff values close to 0.95 for the $\mathrm{CFI}$, cutoff values close or below to 0.06 for the RMSEA, and a cutoff value close to or below 0.08 for the SRMR can be considered as indicating a good fit between the hypothesised model and the observed data.

\section{Results}

Means, variances, correlations, and Cronbach's alpha reliabilities are presented in Table 1. A path model was constructed to examine the cross-lagged associations between the young adults' life satisfaction and engagement in their studies/work. After all the non-significant paths were set to zero, the final model fitted the data well $\left(\chi^{2}(63, N=1538)=\right.$ 161.77, $p=n s, \mathrm{CFI}=.93$, RMSEA $=.03$, SRMR = .07; Figure 1). The results showed that, as expected, despite the high stability of the dependent variables, several cross-lagged paths were identified between study/work engagement and life satisfaction. Life satisfaction, in particular, positively predicted young adults' subsequent study/work engagement in studies (Time 2; s.e. $=.10, p<.05$ ) and higher education/work
(Times 3-5) at the beginning of the participants' third decade $(\mathrm{H} 1)$. In addition, young adults' engagement in higher education studies/work positively predicted their subsequent life satisfaction (Times 4-5) at the beginning of their third decade $(\mathrm{H} 2)$. Further, as expected ( $\mathrm{H} 3$ and $\mathrm{H} 4)$, the results showed that academic performance positively predicted young adults' life satisfaction (s.e. $=.26, p<.001$ ) and study/work engagement (Time 1; s.e. $=.16, p<.001$ ), and that young males showed a higher level of life satisfaction (Time 1; s.e. $=.13, p<.001$ ) than their female counterparts.

In order to examine whether the model would show the same fit for both males and females, and for both students on the academic and those on the vocational track, the analyses were also carried out using the multigroup procedure (Muthén \& Muthén, 1998-2016). In these analyses, the data were divided into two samples: first into males and females, and then into students following an academic and those following a vocational track. Path analyses were then carried out, assuming that all parameters would be equal for these two groups. If the fit of the model was good and no significant modification indices were found, the model would be assumed to fit the groups equally. The results indicated moderately good fit for both models $\left(\chi^{2}(124, N=856)=229.33, p=n s, C F I\right.$ $=.93$, RMSEA $=.05$, SRMR $=.08$ for the gender multigroup model and $\chi^{2}(123, N=755)=255.86, p=$ $n s, \mathrm{CFI}=.91$, RMSEA $=.05$, SRMR $=.09$ for the track multigroup model). No differences related to gender or study track were found in these multigroup analyses.

\section{Discussion}

To summarise, the present study examined the cross-lagged paths between life satisfaction and study and work engagement by following young adults from age 17 to 25 over their transition from postcomprehensive education to higher education or work, and until the beginning of their third decade. The developmental dynamics between life satisfaction and engagement showed that life satisfaction in particular positively predicted young adults' subsequent engagement in their post-comprehensive studies and in higher education or work. Study/work engagement, in turn, predicted young adults' life 
satisfaction after their transition to higher education/work. High initial life satisfaction was more typical among males than females. However, no differences related to gender or academic track were found in the associations between life satisfaction and study/work engagement.

\section{Cross-lagged associations between life satisfaction and study/work engagement}

The first aim of the present study was to investigate the cross-lagged associations between young adults' life satisfaction and engagement during and after their post-comprehensive studies. The results showed that, as expected $(\mathrm{H} 1)$, positive spillover occurred between life satisfaction and engagement (Masten et al., 2010). Confirming our hypotheses, life satisfaction, in particular, positively predicted young adults' subsequent study/work engagement during their post-comprehensive studies and after the transition to higher education/work (H1). Young adults' study/work engagement, in turn, positively predicted their subsequent life satisfaction only later on after the transition to higher education or work at the beginning of the third decade $(\mathrm{H} 2)$. These results are similar to research on flow (Csikszentmihalyi, 1990), an experience which study/work engagement resembles (Upadyaya \& Salmela-Aro, 2013a). Life satisfaction and flow are strongly associated because optimal challenge and being immersed in meaningful activities add to satisfaction (Myers \& Diener, 1995). In our investigation, study or work engagement predicted life satisfaction during the two last measurement points at the beginning of the third decade of life. By this time the young adults had already transitioned to higher education or work, and had probably better adapted to their new educational/occupational environments and experienced stronger stageenvironment fit (Eccles \& Roeser, 2009) than earlier during the transition. Moreover, our results showed that changes occur in these associations over time. Throughout the period of study, when young adults' life satisfaction is high, he/she often has experiences similar to flow and feels more engaged in his/her studies and work. It is also possible that high life satisfaction leads to higher job satisfaction, which in turn increases job engagement (see also Erdogan et al., 2012; Upadyaya \& Salmela-Aro, in press).
Furthermore, these results suggested that study/work engagement becomes increasingly important at the beginning of the third decade when young adults are preparing for adult work roles (Arnett, 2000): wellbeing in one area of life spills over to life in general as a part of developmental cascades (Masten et al., 2010) promoting young adults' adjustment to their adult work roles.

These results thus suggested that aspects of overall wellbeing spill over to domain-specific experiences, which in our study represented flow-like experiences in studies/work. Previous research on burnout symptoms and malaise have shown that the contrary is usually the case. Domain-specific job burnout symptoms spill over to general wellbeing and show as a decrease in one's overall life satisfaction (Hakanen \& Schaufeli, 2012; Salmela-Aro, Savolainen, \& Holopainen, 2009), possibly because job burnout also affects psychological and physiological health (Maslach, Schaufeli, \& Leiter, 2001). There are at least two possible explanations for these differences: first, it is possible that when one's wellbeing is high, the spillover effects between general and domain-specific experiences are positive and are transmitted in the direction from general wellbeing to domain-specific, whereas when one's wellbeing is low, the spillover effects between general and domain- specific experiences are negative and are transmitted in the opposite direction. However, the results of this study suggest a developmental trend. During the transition to higher education/work (at the beginning of the third decade), when the young adults are adapting to a new study/work environment, study/work-specific experiences might be more affected by one's overall wellbeing, whereas later on while facing the new study/work demands and challenges, study/workspecific experiences increasingly spill over to general wellbeing.

\section{Antecedents of life satisfaction and study/work engagement}

In this study, the antecedents of life satisfaction and study/work engagement were similar to those of several previous studies. Young males experienced a higher level of life satisfaction than young females (Marks, 2000; Diseth et al., 2012), and academic performance positively predicted young adults' initial life satisfaction (Suldo, Riley, \& Shaffer, 2006) and 
study/work engagement (Li \& Lerner, 2011; SalmelaAro \& Upadyaya, 2012), as expected (H3 and H4). However, no differences related to gender or academic track emerged in the developmental dynamics of life satisfaction and study/work engagement. These results suggest that the longitudinal associations between life satisfaction and study/work engagement are similar for males and females and for young adults following either a vocational or academic track (see also Huebner et al., 2000).

\section{Limitations and future directions}

Several limitations should be taken into consideration when generalising the results of the present study. First, this study focused on young adults during their post-comprehensive education and over their transition to higher education/work. Thus, the results can be generalised only to the same age group. It is possible that the associations between life satisfaction and study/work engagement would have been different had different age groups been studied (see also Fredricks et al., 2004). More studies are needed to examine these associations among a range of age groups. Second, some of the parameters reported in the present study had relatively small values, probably due to the high stability of life satisfaction and study/work engagement. Future studies are needed to confirm these results. Third, young adults who participated in the study at each measurement time showed higher engagement at the beginning of this study and higher life satisfaction towards the end of the study. Fourth, our results only described the associations between overall life satisfaction and study/work engagement, whereas it is possible that the associations between life satisfaction and the separate engagement dimensions would have been more pronounced. Fifth, it is also possible that various latent trajectory groups exist that reflect different levels and development of study/work engagement and life satisfaction. For example, some young adults may experience an overall high level of engagement and life satisfaction whereas among other young adults, engagement and life satisfaction may change across educational/work transitions. Research utilising a longitudinal design and varying study/work contexts is needed to examine these associations further. Finally, causal inferences are limited owing to the possibility that other, unmeasured variables, such as support from parents (Simons-Morton \& Crump, 2003; Upadyaya \& Salmela-Aro, 2013a, 2013b) and teachers (Murray, 2009), may have contributed to the results. The data presented in this study was also gathered before, during, and after the Great Recession, which might have heightened young adults' concern about adjusting to the new educational/work environments and increased the importance of engagement for life satisfaction.

\section{Conclusions}

The results of this study showed that young adults' life satisfaction predicted their study/work engagement across the transition from postcomprehensive studies to higher education/work and at the beginning of the participants' third decade, whereas study/work engagement predicted young adults' life satisfaction only after the transition to higher education or work at the beginning of their third decade. These results showed that third decade is an important period when wellbeing in one area of life easily spills over to another area of life. Moreover, during the third decade spillover occurs between general and domain-specific characteristics of wellbeing in both directions, whereas earlier during the second decade spillover only occurs from life satisfaction to study/work engagement.. These developmental changes may be due to the changes in stage-environment-fit (Eccles \& Roeser, 2009) and reflect young adults' phase-adequate engagement (Dietrich et al., 2012). In addition, these findings supported the ideas of the broaden-and-build theory according to which students who are satisfied with their studies and life, and experience frequent positive emotions, also exhibit adaptive coping behaviours, feel more engaged, and gain more resources, which, in turn, promote positive upward spirals of success in studies/work (see also Fredrickson, 2001). Thus, in future research and education it would be important to take into the account the role of life satisfaction, as it is important in maintaining one's psychological wellbeing and in shaping one's engagement and other experiences in studies/work, and in supporting one's further 
development across the life course. The indicators of general wellbeing (e.g., life satisfaction, happiness) may also spill over to academic/work-related engagement, help in adapting to new study/work environments (see also Masten et al., 2010), increase stage-environment fit (Eccles \& Roeser, 2009), and support the young person's life course development (Haase et al., 2008).

\section{Acknowledgements}

The research reported in this article has been funded by grants from the Jacobs Foundation, the Finnish Work Environmental Fund, and from the Academy of Finland (134931, 139168).

\section{References}

Annunziata, D., Hogue, A., Faw, L., \& Liddle, H. A. (2006). Family functioning and school success in at-risk, inner-city adolescents. Journal of Youth and Adolescence, 35, 105-113. https://doi.org/10.1007/s10964-005-9016-3

Archambault, I., Janosz, M., Morizot, J., \& Pagani, L. (2009). Adolescent behavioral, affective, and cognitive engagement in school: Relations to dropout. Journal of School Health, 79, 408-415. https://doi.org/10.1111/j.1746-1561.2009.00428.x

Arnett, J. J. (2000). Emerging adulthood: A theory of development from the late teens through the twenties. American psychologist, 55(5), 469. https://doi.org/10.1037/0003-066X.55.5.469

Babin, B. J., \& Boles, J. S. (1998). Employee behavior in a service environment: a model and test of potential differences between men and women. The Journal of Marketing, 77-91. https://doi.org/10.2307/1252162

Berndt, T. J., \& Miller, K. E. (1990). Expectancies, values, and achievement in junior high school. Journal of Educational Psychology, 82, 319-326. https://doi.org/10.1037/0022-0663.82.2.319

Caspi, A. (2002). 11 Social selection, social causation, and developmental pathways: empirical strategies for better understanding how individuals and environments are linked across the life-course. Paths to successful development: Personality in the life course, 281.

Cohn, M. A., Fredrickson, B. L., Brown, S. L., Mikels, J. A., \& Conway, A. M. (2009). Happiness unpacked: positive emotions increase life satisfaction by building resilience. Emotion, 9(3), 361. https://doi.org/10.1037/a0015952

Csikszentmihalyi, M. (1990). Flow: The psychology of optimal experience. Harper and Row: New York.

Demerouti, E., Bakker, A., Nachreiner, F. \& Schaufeli, W. (2001). The job demands resources model of burnout. Journal of Applied Psychology, 86, 499-512. https://doi.org/10.1037/0021-9010.86.3.499

Diener, E. D., Emmons, R. A., Larsen, R. J., \& Griffin, S. (1985). The satisfaction with life scale. Journal of personality assessment, 49(1), 71-75. https://doi.org/10.1207/s15327752jpa4901 13

Dietrich, J., Parker, P., \& Salmela-Aro, K. (2012). Phase-adequate engagement at the post-school transition. Developmental psychology, 48(6), 1575. https://doi.org/10.1037/a0030188

Diseth, Å., Danielsen, A. G., Samdal, O. (2012). A path analysis of basic need support, self-efficacy, achievement goals, life satisfaction and academic achievement level among secondary school students. Educational Psychology: An International Journal of Experimental Educational Psychology, 32, 335-354. https://doi.org/10.1080/01443410.2012.657159

Eccles, J.S. \& Roeser, R.W. (2009). Schools, Academic Motivation, and Stage-Environment Fit. In R.M. Lerner and L. Steinberg (Eds.) Handbook of Adolescent Psychology (3rd ed.)(pp. 404-434). Hoboken, N.J.: John Wiley \& Sons. https://doi.org/10.1002/9780470479193.adlpsy001013

Elder, G. H. \& Shanahan, M. J. (2006). The life course and human development. In R. M. Lerner (Ed.). Handbook of Child Psychology, Vol. 1: Theoretical models of human development (pp. 665-715). Editors-in-chief: W. Damon \& R. M. Lerner. Hoboken, NJ: John Wiley \& Sons. 
Elmore, G. M. \& Huebner, S. E. (2010). Adolescents' satisfaction with school experiences: Relationships with demographics, attachment relationships, and school engagement behavior. Psychology in the Schools, 47, 525-537.https://doi.org/10.1002/pits.20488

Erdogan, B., Bauer, T. N., Truxillo, D. M., \& Mansfield, L. R. (2012). Whistle While You Work: A Review of the Life Satisfaction Literature. Journal of Management, 38(4), 1038-1083. https://doi.org/10.1177/0149206311429379

Evans, K. (2007). Concepts of bounded agency in education, work, and the personal lives of young adults. International journal of psychology, 42(2), 85-93. https://doi.org/10.1080/00207590600991237

Ford, M. T., Heinen, B. A., \& Langkamer, K. L. (2007). Work and family satisfaction and conflict: A meta-analysis of cross-domain relations. Journal of Applied Psychology, 92. https://doi.org/10.1037/0021-9010.92.1.57

Fredricks, J. A., Blumenfeld, P. C. \& Paris, A. H. (2004). School engagement: Potential of the concept, state of the evidence. Review of Educational Research, 74, 59-109. https://doi.org/10.3102/00346543074001059

Fredrickson, B. L. (2001). The role of positive emotions in positive psychology: The broaden-and-build theory of positive emotions. American psychologist, 56(3), 218. https://doi.org/10.1037/0003-066X.56.3.218

Haase, C. M., Heckhausen, J., \& Köller, O. (2008). Goal engagement during the school-work transition: Beneficial for all, particularly for girls. Journal of Research on Adolescence, 18(4), 671-698. https://doi.org/10.1111/i.1532-7795.2008.00576.x

Hakanen, J. J., Bakker, A. B., \& Schaufeli, W. B. (2006). Burnout and work engagement among teachers. Journal of school psychology, 43(6), 495-513. https://doi.org/10.1016/j.jsp.2005.11.001

Hakanen, J. J. \& Schaufeli, W. B. (2012). Do burnout and work engagement predict depressive symptoms and life satisfaction? A three-wave seven year prospective study. Journal of affective disorders, 141(2), 415-424. https://doi.org/10.1016/j.jad.2012.02.043

Harter, J. K., Schmidt, F. L., \& Hayes, T. L. (2002). Business-unit-level relationship between employee satisfaction, employee engagement, and business outcomes: A meta-analysis. Journal of Applied Psychology, 87, 268279. https://doi.org/10.1037/0021-9010.87.2.268

Hu, L. T., \& Bentler, P. M. (1999). Cutoff criteria for fit indexes in covariance structure analysis: Conventional criteria versus new alternatives. Structural equation modeling: a multidisciplinary journal, 6(1), 1-55. https://doi.org/10.1080/10705519909540118

Huebner, E. S., Drane, W., \& Valois, R. F. (2000). Levels and demographic correlates of adolescent life satisfaction reports. School Psychology International, 21, 281-292. https://doi.org/10.1177/0143034300213005

Huebner, E. S., Valois, R. F., Paxton, R., \& Drane, W. (2005). Middle school students' perceptions of quality of life. Journal of Happiness Studies, 6, 15-24. https://doi.org/10.1007/s10902-004-1170-x

Jones, M. D. (2006). Which is a better predictor of job performance: Job satisfaction or life satisfaction. Journal of Behavioral and Applied Management, 8(1), 20-42.

Kuopion Lukiokoulutus (2009). Tietoja Kuopion kaupungin lukioista LV. 2009-2010. Retrieved from http://www.kuopio.fi/attachments.nsf/Files/031209121333543/\$FILE/Tilastot\%20Kuopion\%20kaupungin\% 20lukioistalv2009_2010._versio3_lopullinen_ilman\%20esitetta.pdf

Langelaan, S., Bakker, A. B., Van Doornen, L. J., \& Schaufeli, W. B. (2006). Burnout and work engagement: Do individual differences make a difference? Personality and Individual Differences, 40(3), 521-532. https://doi.org/10.1016/j.paid.2005.07.009

Lewis, A. D., Huebner, E. S., Malone, P. S., \& Valois, R. F. (2011). Life satisfaction and student engagement in adolescents. Journal of Youth and Adolescence, 40, 249-262. https://doi.org/10.1007/s10964-010-9517-6

Li, Y. \& Lerner, R. M. (2011). Trajectories of school engagement during adolescence: Implications for grades, depression, delinquency, and substance use. Developmental Pscyhology, 47, 233-247. https://doi.org/10.1037/a0021307

Linnakylä, P. \& Malin, A. (2008). Finnish students' school engagement profiles in the light of PISA 2003. Scandinavian Journal of Educational Research, 52, 583-602. https://doi.org/10.1080/00313830802497174 
Louis, V. V., \& Zhao, S. (2002). Effects of family structure, family SES, and adulthood experiences on life satisfaction. Journal of Family Issues, 23(8), 986-1005. https://doi.org/10.1177/019251302237300

Marks, H. M. (2000). Student engagement in instructional activity: Patterns in the elementary, middle, and high school years. American Educational Research Journal, 37, 153-184. https://doi.org/10.3102/00028312037001153

Maslach, C., Schaufeli, W. B., \& Leiter, M. P. (2001). Job burnout. Annual Review of Psychology, 52(1), 397-422. https://doi.org/10.1146/annurev.psych.52.1.397

Masten, A. S., Desjardins, C. D., McCormick, C. M., Kuo, Sally I-Chun, \& Long, J. D. (2010). The significance of childhood competence and problems for adult success in work: A developmental cascade analysis Development and Psychopatology, 22, 679-694.

Moazami-Goodarzi, A., Nurmi, J.-E., Mauno, S. \& Rantanen, J. (2014). Cross-lagged relations between work-family enrichment, vigor at work, and core self-evaluations: A three-wave study. Journal of Business and Psychology, 1-10.

Murray, C. (2009). Parent and teacher relationships as predictors of school engagement and functioning among low-income urban youth. Journal of Early Adolescence, 29, 376-404. https://doi.org/10.1177/0272431608322940

Muthén, L., \& Muthén, B. O. (1998-2016af). Mplus. User's guide. Los Angeles, CA: Muthén \& Muthén.

Myers, D. G., \& Diener, E. (1995). Who is happy? Psychological science, 6(1), 10-19. https://doi.org/10.1111/j.14679280.1995.tb00298.x

Ou, S. R. (2008). Do GED recipients differ from graduates and school dropouts? Findings from an inner-city cohort. Urban Education, 43(1), 83-117. https://doi.org/10.1177/0042085907305187

Pavot, W., \& Diener, E. (1993). Review of the satisfaction with life scale. Psychological assessment, 5(2), 164. https://doi.org/10.1037/1040-3590.5.2.164

Perdue, N. H., Manzeske, D. P., \& Estell, D. B. (2009). Early predictors of school engagement: Exploring the role of peer relationships. Psychology in the Schools, 46, 1084-1097. https://doi.org/10.1002/pits.20446

Pomerantz, E. M., Altermatt, E. R., \& Saxon, J. L. (2002). Making the grade but feeling distressed: Gender differences in academic performance and internal distress. Journal of Educational Psychology, 94, 396-404. https://doi.org/10.1037/0022-0663.94.2.396

Rindfuss, R. R. (1991). The young adult years: Diversity, structural change, and fertility. Demography, 28(4), 493512. https://doi.org/10.2307/2061419

Salanova, M., Agut, S., \& Peiro, J. M. (2005). Linking organizational resources and work engagement to employee performance and customer loyalty: The mediation of service climate. Journal of Applied Psychology, 90, 1217-1227. https://doi.org/10.1037/0021-9010.90.6.1217

Salmela-Aro, K., Kiuru, N., \& Nurmi, J.-E. (2008). The role of educational track in adolescents' school burnout: A longitudinal study. British Journal of Educational Psychology, 78, 663-689. https://doi.org/10.1348/000709908X281628

Salmela-Aro, K., Savolainen, H., \& Holopainen, L. (2009). Depressive symptoms and school burnout during adolescence: Evidence from two cross-lagged longitudinal studies. Journal of Youth and Adolescence, 38(10), 1316-1327. https://doi.org/10.1007/s10964-008-9334-3

Salmela-Aro, K. \& Upadyaya, K. (2012). The Schoolwork Engagement Inventory: Energy, Dedication and Absorption (EDA). European Journal of Psychological Assessment, 28, 60-67. https://doi.org/10.1027/10155759/a000091

Salmela-Aro, K. \& Upadyaya, K. (2014). School Burnout and Engagement in the Context of the Demands-Resources Model. British Journal of Educational Psychology, 84, 137-151. https://doi.org/10.1111/bjep.12018

Schaufeli, W. B., Bakker, A. B., \& Salanova, M. (2006). The measurement of work engagement with a short questionnaire: A cross-national study. Educational and Psychological Measurement, 66, 701-716. https://doi.org/10.1177/0013164405282471 
Schaufeli, W. B., Martinez, I., Pinto, A. M., Salanova, M., \& Bakker, A. (2002). Burnout and engagement in university students: A cross-national study. Journal of Cross-Cultural Psychology, 33, 5, 464-481. https://doi.org/10.1177/0022022102033005003

Schaufeli, W. B., Salanova, M., Gonzalez-Roma, V., \& Bakker, A. B. (2002). The measurement of engagement and burnout: A two sample confirmatory factor analytic approach. Journal of Happiness Studies, 3, 71-92. https://doi.org/10.1023/A:1015630930326

School Statistics. (2010). http://www.stat.fi/til/khak/2010/khak 2010 2011-12-13_tau_001_fi.html. Helsinki: Central Statistical Office of Finland.

Seligman, M. E. P. \& Csikszentmihalyi, M. (2000). Positive psychology: An introduction. American Psychologist, 55, 514. https://doi.org/10.1037/0003-066X.55.1.5

Seligson, J. L., Huebner, E. S., \& Valois, R. F. (2003). Preliminary validation of the brief multidimensional students' life satisfaction scale (BMSLSS). Social Indicators Research, 61(2), 121-145. https://doi.org/10.1023/A:1021326822957

Seppälä, P., Mauno, S., Feldt, T., Hakanen, J., Kinnunen, U., Tolvanen, A., \& Schaufeli, W. (2009). The construct validity of the Utrecht Work Engagement Scale: Multisample and longitudinal evidence. Journal of Happiness Studies, 10(4), 459-481. https://doi.org/10.1007/s10902-008-9100-y

Simons-Morton, B. G. \& Crump, A. D. (2003). Association of parental involvement and social competence with school adjustment and engagement among sixth graders. Journal of School Health, 73, 121-126. https://doi.org/10.1111/j.1746-1561.2003.tb03586.x

Suldo, S. M., \& Huebner, E. S. (2006). Is extremely high life satisfaction during adolescence advantageous?. Social indicators research, 78(2), 179-203. https://doi.org/10.1007/s11205-005-8208-2

Suldo, S. M., Riley, K. N., \& Shaffer, E. J. (2006). Academic correlates of children and adolescents' life satisfaction. School Psychology International, 27(5), 567-582. https://doi.org/10.1177/0143034306073411

Upadyaya, K. Salmela-Aro, K. (2013a). Development of school engagement in association with academic success and well-being in varying social contexts: A review of empirical research. European Psychologist, 18, 136147. https://doi.org/10.1027/1016-9040/a000143

Upadyaya, K. Salmela-Aro, K. (2013b). Engagement with studies and work: Trajectories from post-comprehensive school education to higher education and work. Emerging Adulthood, 1, 247-257. https://doi.org/10.1177/2167696813484299

Upadyaya, K., \& Salmela-Aro, K. (2014). Cross-lagged associations between study and work engagement dimensions during young adulthood. The Journal of Positive Psychology, (ahead-of-print), 1-13.

Upadyaya, K., Vartiainen, M. \& Salmela-Aro, K. (2015). From servant leadership to work engagement, life satisfaction, and occupational health: Job demands and resources. Burnout Research, 3(4), 101-108. https://doi.org/10.1016/j.burn.2016.10.001

Upadyaya, K., \& Salmela-Aro, K. (in press). Development of early vocational behavior: Parallel associations between career engagement and satisfaction. Journal of Vocational Behavior. https://doi.org/10.1016/j.jvb.2015.07.008

Wefald, A. J., \& Downey, R. G. (2009). Construct dimensionality of engagement and its relation with satisfaction. The Journal of Psychology, 143(1), 91-112. https://doi.org/10.3200/JRLP.143.1.91-112 
Table 1. Means, variances, Pearson Correlation Coefficients, and Cronbach's Alpha Reliabilities.

\begin{tabular}{|c|c|c|c|c|c|c|c|c|c|c|c|c|c|c|}
\hline & SWE1 & SWE 2 & SWE 3 & SWE 4 & SWE 5 & Life 1 & Life 2 & Life 3 & Life 4 & Life 5 & Gender & GPA & Track & SES \\
\hline \multicolumn{15}{|l|}{$\overline{\text { SWE } 1}$} \\
\hline SWE 2 & $.58 * * *$ & & & & & & & & & & & & & \\
\hline SWE 3 & $.29 * * *$ & $.36 * * *$ & & & & & & & & & & & & \\
\hline SWE 4 & $.31^{* * *}$ & $.30 * * *$ & $.45^{* * *}$ & & & & & & & & & & & \\
\hline SWE 5 & $.28 * * *$ & $.28 * * *$ & $.34 * * *$ & $.45^{* * *}$ & & & & & & & & & & \\
\hline Life 1 & $.38 * * *$ & $.30 * * *$ & $.19 * * *$ & $.26 * * *$ & $.20 * * *$ & & & & & & & & & \\
\hline Life 2 & $.27^{* * *}$ & $.33 * * *$ & $.21^{* * *}$ & $.24^{* * *}$ & $.18^{* * *}$ & $.64^{* * *}$ & & & & & & & & \\
\hline Life 3 & $.14^{* *}$ & $.16^{* *}$ & $.30 * * *$ & $.27 * * *$ & $.23 * * *$ & $.40 * * *$ & $.52 * * *$ & & & & & & & \\
\hline Life 4 & $.17^{* * *}$ & $.19 * * *$ & $.25^{* * *}$ & $.43 * * *$ & $.29 * * *$ & $.40 * * *$ & $.47 * * *$ & $.61^{* * *}$ & & & & & & \\
\hline Life 5 & $.24 * * *$ & $.22 * * *$ & $.25^{* * *}$ & $.34 * * *$ & $.36^{* * *}$ & $.33^{* * *}$ & $.35 * * *$ & $.42 * * *$ & $.57 * * *$ & & & & & \\
\hline Gender & .03 & -.02 & -.05 & .02 & -.01 & $.14^{* * *}$ & $.14^{* * *}$ & .04 & .03 & $-.08 * *$ & & & & \\
\hline GPA & $.23 * * *$ & $.25 * * *$ & 0.01 & .05 & .04 & $.28 * * *$ & $.24^{* * *}$ & $.18^{* * *}$ & $.17^{* *}$ & .09 & $-.30 * * *$ & & & \\
\hline Track & -.11 & $-.21 *$ & $-.11 *$ & .03 & .07 & -.05 & .01 & .03 & .04 & .02 & -.05 & $.60 * * *$ & & \\
\hline SES & -.06 & -.01 & -.05 & -.02 & -.05 & -.02 & -.02 & .08 & .05 & -.02 & -.02 & $.20 * * *$ & $.22 * * *$ & \\
\hline$M$ & 3.56 & 3.46 & 4.33 & 4.21 & 4.38 & 4.77 & 4.80 & 4.61 & 4.75 & 4.39 & 1.54 & 7.89 & 0.55 & 1.70 \\
\hline Var & 1.74 & 1.74 & 1.26 & 1.44 & 1.40 & 1.62 & 1.56 & 1.63 & 1.60 & 1.82 & 0.27 & 0.75 & 0.26 & 0.15 \\
\hline $\begin{array}{l}\text { Cronbach's } \\
\alpha\end{array}$ & .94 & .94 & .93 & .94 & .94 & .89 & .89 & .87 & .87 & .89 & - & - & - & - \\
\hline
\end{tabular}

Note. ${ }^{* * *} p<.001 ; * * p<.01 ; * p<.05$

Note. SWE = study/work engagement; Life = life satisfaction; $1=$ Time 1 (age = 17, $N=818) ; 2=$ Time 2 (age = 18, $N=749) ; 3=$ Time 3 (age = $21, N=611) ; 4=$ Time 4 (age $=23, N=561) ; 5=$ Time 5 (age $=25, N=533)$. 


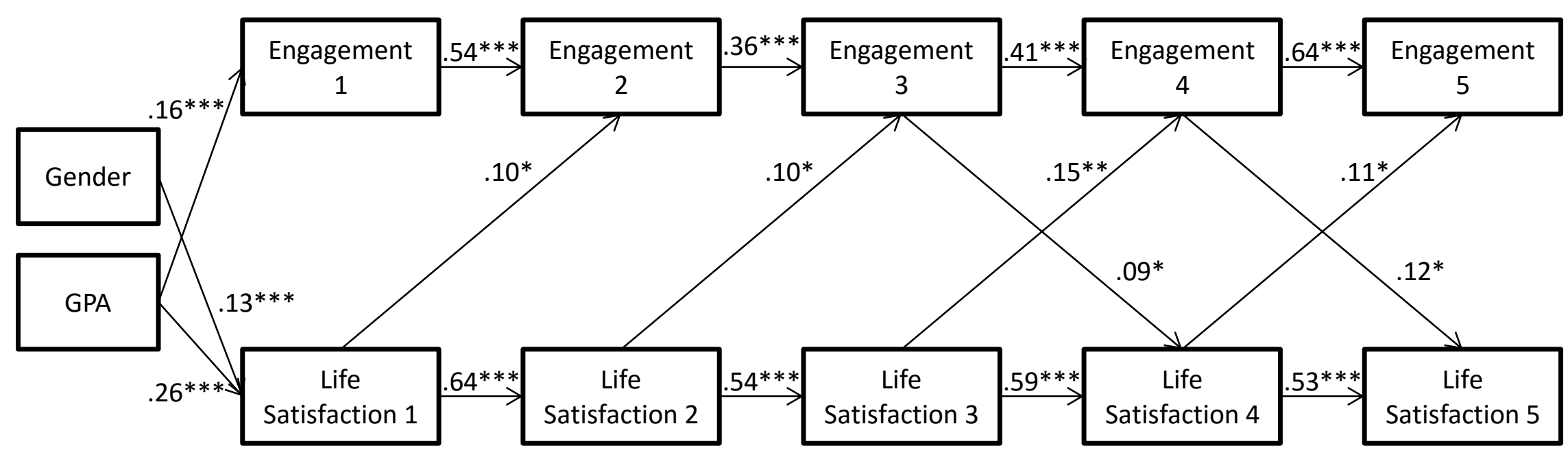

$\begin{array}{lllll}\text { Age }=17 & \text { Age }=18 & \text { Age }=21 & \text { Age }=23 & \text { Age }=25 \\ \mathrm{~N}=818 & \mathrm{~N}=749 & \mathrm{~N}=611 & \mathrm{~N}=561 & \mathrm{~N}=533 \\ & & & \\ \text { Post-comprehensive } & \text { Transition } & \text { Higher education / work }\end{array}$

Figure 1. Cross-lagged associations between young adults' life satisfaction and engagement in studies/work (Standardised estimates). Note. ${ }^{* *} p<.001 ;{ }^{* *} p<.01 ;{ }^{*} p<.05 ; 1=$ Time 1, $2=$ Time 2; $3=$ Time 3; 4 = Time 4; $5=$ Time 5 . 